\title{
Industrial Applications of High-Power Copper Vapor Lasers
}

\author{
RECEIVED \\ OCT 111995

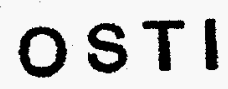

B. E. Warner, C. D. Boley, J. J. Chang, E. P. Dragon,

M. A. Havstad, M. Martinez, and W. McLean II

This paper was prepared for submittal to the NATO Advanced Research Workshop on Pulsed Metal Vapour Lasers

St. Andrews, Scotland

August 7-10, 1995

\section{August 1, 1995}

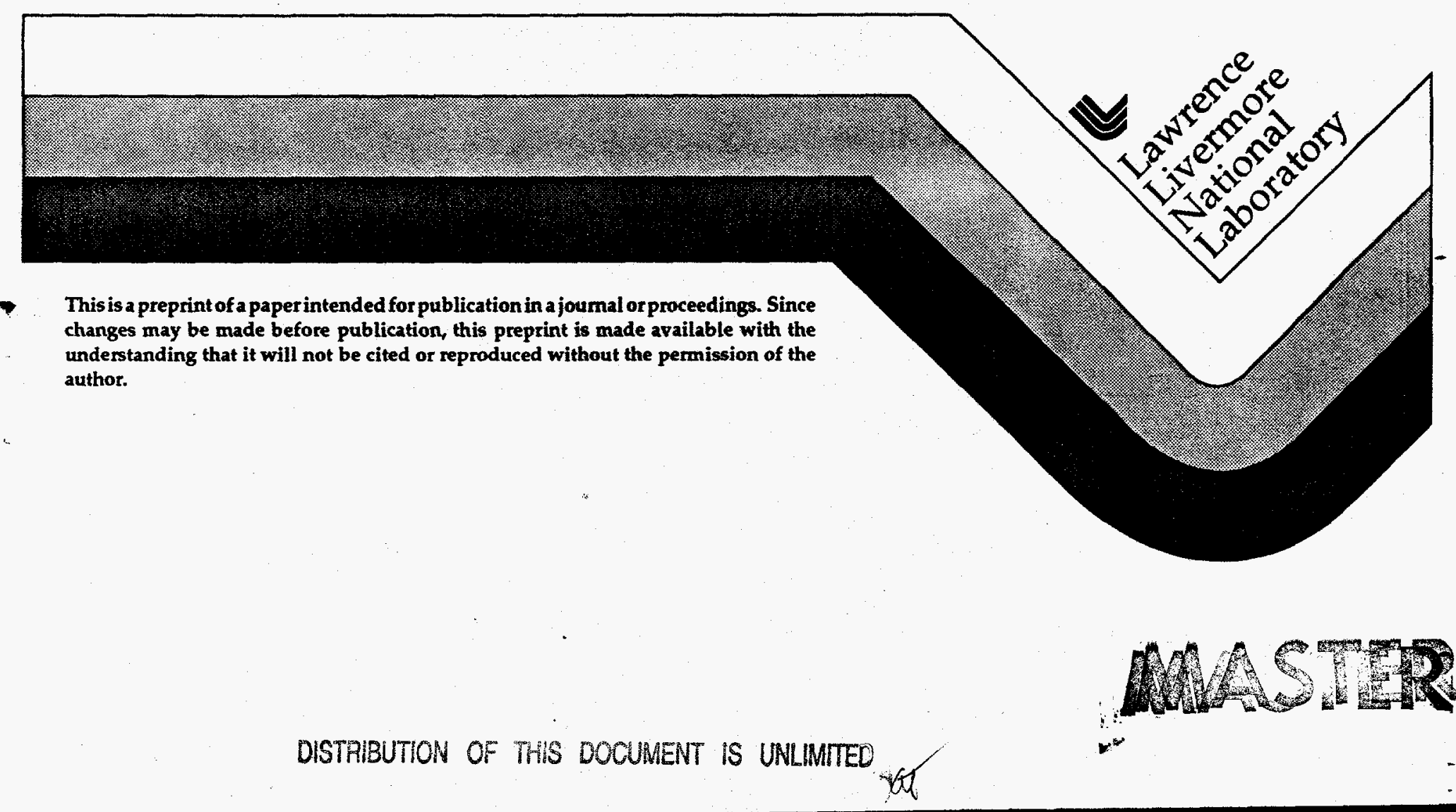




\section{DISCLAIMER}

This document was prepared as an account of work sponsored by an agency of the United States Government. Neither the United States Government nor the University of California nor any of their employees, makes any warranty, express or implied, or assumes any legal liability or responsibility for the accuracy, completeness, or usefulness of any information, apparatus, product, or process disclosed, or represents that its use would not infringe privately owned rights. Reference herein to any specific commercial product, process, or service by trade name, trademark, manufacturer, or otherwise, does not necessarily constitute or imply its endorsement, recommendation, or favoring by the United States Government or the University of California. The views and opinions of authors expressed herein do not necessarily state or reflect those of the United States Government or the University of California, and shall not be used for advertising or product endorsement purposes. 


\section{DISCLAIMER}

Portions of this document may be illegible in electronic image products. Images are produced from the best available original document. 


\title{
INDUSTRIALAPPLICATIONS OF HIGH-POWER COPPER VAPOR LASERS
}

\author{
BRUCE E. WARNER, CHARLES D. BOLEY, JM J. CHANG, \\ ERNEST P. DRAGON, MARK A. HAVSTAD, MARK MARTINEZ, \\ AND WILLIAM MCLEAN II \\ Lawrence Livermore National Laboratory \\ P.O. Box 5508, MS L-467, Livermore, CA, 94551, USA
}

\begin{abstract}
A growing appreciation has developed in the last several years for the copper vapor laser because of its utility in ablating difficult materials at high rates. Laser ablation at high rates shows promise for numerous industrial applications such as thin film deposition, precision hole drilling, and machining of ceramics and other refractories.
\end{abstract}

\section{Introduction}

Since its invention is the late 1960s [1], the copper vapor laser has been developed predominantly for laser isotope separation [2]. In this application the laser is valued because of its wavelength, 50 ns pulses, multi-kilohertz repetition rate, and $1-2 \%$ electrical to optical efficiency. As this laser system has matured into an industrial tool, new material processing applications for the laser have developed. When applied to materials processing, the visible wavelength is found to couple well to most materials, the short pulse length causes ablative material removal, and the high repetition rate increases the material removal rate to a moderate level. A further advantage of the laser is near diffraction-limited operation at hundreds of watts average power, allowing precise spatial control.

This paper is segmented into three major sections; a review of modeling and measurements that help illuminate the physics of copper laser beam - material interaction and a discussion of two applications of high-power copper lasers, precision hole drilling and pulsed laser deposition. In each of these applications the unique suitability of the copper laser will be discussed along with results of tests performed at LLNL.

\section{Physics of copper laser beam - material interaction}

Over the past couple of years LLNL has investigated both a one-dimensional model and experimental measurements of copper laser beam/material interactions. This effort has helped aid our understanding of the influence of processing parameters (irradiance and material type) and on material processing (material removal rate). First in this section is a discussion of the model with results and subsequently, a discussion of measurements of a plume expansion off of an aluminum target. 
The model involves a one-dimensional description of heat transport below a surface, hydrodynamic expansion of the vapor and compressed air, and light propagation through the vapor to the vaporization surface $[3,4]$. Figure 1 details the geometry of the model. On the left lies the solid material. Laser light strikes the surface (from the right in the figure), causing a melt layer to develop and propagate inward into the solid material. When the vaporization temperature is reached, the vapor begins to blow off, preceded by a plug of compressed air. This is bounded by a shock front. When the temperature becomes sufficiently high, both the incident beam and the reflected beam (to the extent that it is appreciable) can be absorbed in the vapor by photoionization and inverse bremsstrahlung.

The pressure and energy of the vapor require an equation of state. Since substantial ionization may be present in the bulk of the vapor, the electronic contributions that the pressure and energy density must be considered). Simple estimates show that, for time scales longer than a few nanoseconds, the assumption of local thermodynamic equilibrium is fairly well justified. Hence we have developed and utilized a Saha equation of state package, assuming hydrogen-like levels between ionization limits. It agrees with more sophisticated codes in the regime of interest. The total pressure is $p=(n+n e) k T$.

For the calculations reported here, a $510.6 \mathrm{~nm}$ beam is incident on stainless steel at an average irradiance of $101^{\circ} \mathrm{W} / \mathrm{cm}^{2}$ (i.e.. $45 \mathrm{~W}$ at $4.5 \mathrm{kHz}$ with a spot size of $50 \mu \mathrm{m}$ ). The temporal light pulse rises rapidly to a maximum in $8 \mathrm{~ns}$, and falls off to $10 \%$ of maximum at $70 \mathrm{~ns}$. The ambient atmosphere is assumed to be air, though no chemical reactions are modeled. Figure 2 displays the material temperature spatial profiles for three times after the light is first incident on the surface. Note that $\mathrm{z}=0$ is the original surface position. At $30 \mathrm{~ns}$, the ablating surface temperature is $6500 \mathrm{C}$, having already peaked at $12,000 \mathrm{C}$ after $5 \mathrm{~ns}$ of expose to the beam. At $30 \mathrm{~ns}, 0.5 \mu \mathrm{m}$ of the steel has been removed by vaporization. As displayed by the $30 \mathrm{~ns}$ curve, the temperature gradient into the steel is quite steep; the material $2 \mu \mathrm{m}$ from the original surface is only starting to be heated!

At later times the light pulse is over and consequently the surface temperature has dropped. In addition, our model indicates that at the longest time, 1.1 microns of steel has been ablated with 8 microns of material that have been raised above the melting temperature but not vaporized.

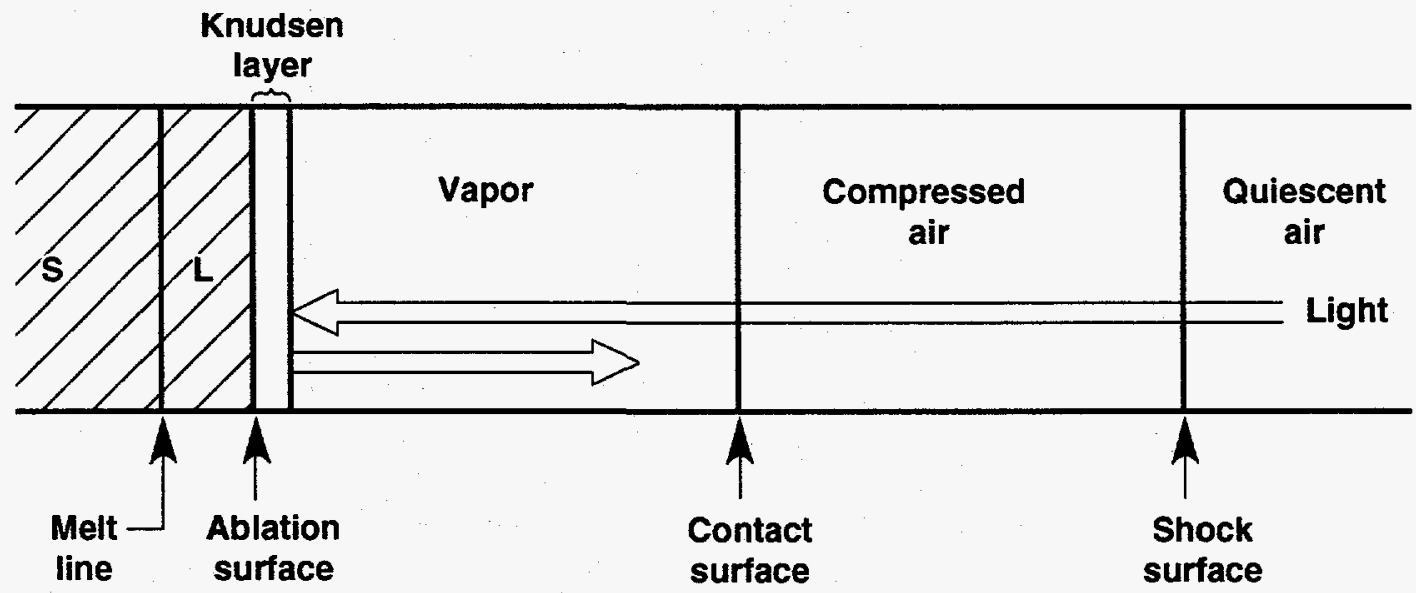

Figure 1. Geometry of the laser ablation model (not to scale). 
(a)

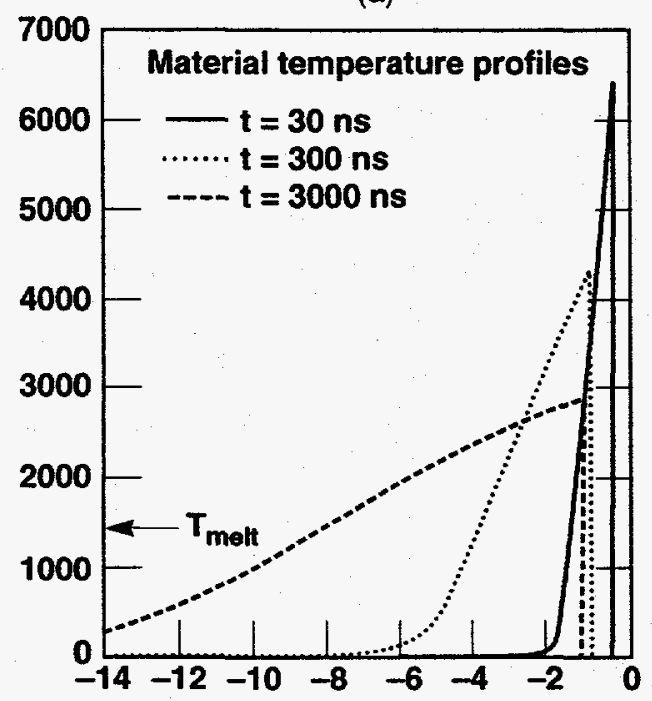

(b)

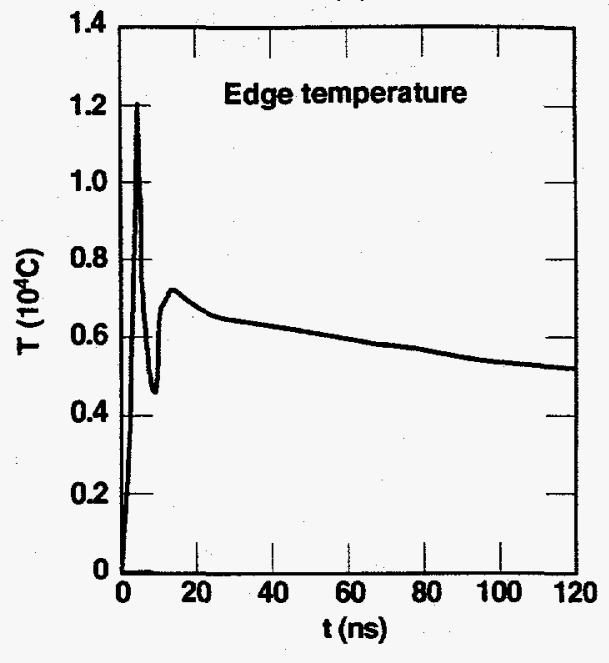

Figure 2. Temperature profiles of the stainless steel material. Note $\mathrm{z}$ is the dimension into the surface.

The response of the material during the laser pulse is dominated by two phases at $1010 \mathrm{~W} /$ $\mathrm{cm}^{2}$. Early in the pulse the surface rapidly heats by direct laser illumination to $12,000 \mathrm{C}$, quickly propagating a vapor front with air being pushed by it. Our code indicates that under these conditions, a second phase occurs. At $8 \mathrm{~ns}$, the laser beam is then nearly completely absorbed by this propagating vapor plume because of photoionization of the vapor. From $8 \mathrm{~ns}$ until $12 \mathrm{~ns}$ the surface receives negligible direct laser heating. As the vapor continues to expand, a small fraction of the laser beam (about $5 \%$ of the incident laser energy) transmits through the vapor to the ablating surface. Common terminology for this phenomena is laser detonation, see reference [5]. Our calculations indicate that $15 \%$ of the laser pulse energy directly heated the vaporization surface, and $85 \%$ of the energy was conducted to it by electron thermal conduction. The thermal conduction phase starts shortly after the laser detonation wave (12 ns) and lasts several microseconds. During this phase the surface temperature slowly decays from $6000 \mathrm{C}$ to $3000 \mathrm{C}$.

Our model indicates that laser detonation occurs on steel at irradiance above $3 \times 108 \mathrm{~W} / \mathrm{cm}^{2}$. Calculations for aluminum show similar thresholds. In the high intensity regime most of the energy transported to the surface is by electron thermal conduction from the vapor plume. Our calculations (and measurements) indicate that at $50 \mathrm{~ns}$ after initial illumination, the vapor front can be a large fraction of a $\mathrm{mm}$ in lateral dimension. This is many times the diameter of the laser spot, implying a loss of spatial control after laser detonation occurs.

We have measured important properties of copper laser beam/material interaction. From these measurements, estimates of vapor density, vapor temperature, surface temperature and pressure can be made through hydrodynamic relationships. In addition, onset of plasma shielding (laser detonation) are easily observed.

Standard shadow and Schlieren techniques were used in our experiments. A Q-switched and frequency-doubled YAG laser was used as a light source with $20 \mathrm{~ns}$ duration. In addition, a short 
pulse flash lamp was also used in combination with a gated (20 ns) camera. In each case the vapor plume was imaged onto the cameras by an achromatic lens with sufficient magnification to yield $\sim 50$ micron resolution. Fresh target material was constantly supplied after each laser pulse via a rotating target. The vapor plume was produced under ambient air without any assist gas.

Figure 3 illustrates images of vapor expansion when laser light was focused on an aluminum target. At a laser intensity of $0.93 \times 109 \mathrm{~W} / \mathrm{cm}^{2}$, the vapor leaves the surface in an expected spherical expansion with a well defined vapor front. As the laser intensity is increased, an additional cone-shaped plume starts to appear. At $7.3 \times 10^{9} \mathrm{~W} / \mathrm{cm}^{2}$, the cone shaped expansion is well defined (figure 3 ). This feature is not correlated with the position of the surface, but with the direction of the incoming laser beam. This strongly suggests that the cone-shaped plume was initiated through a strong plasma absorption of laser light that generated a laser supported detonation wave. Our measurements at various laser intensities indicate that the laser threshold for this plasma ignition is approximately $1.5 \times 10^{9} \mathrm{~W} / \mathrm{cm}^{2}$ for carbon steel and $2 \times 10^{9} \mathrm{~W} / \mathrm{cm}^{2}$ for aluminum. These measured thresholds are within a factor of 5 of those predicted by our onedimensional computer code.

We have measured vapor expansion dynamics and electron temperature and density by line emission spectroscopy. By iterative application of hydrodynamic relationships for adiabatic shock expansion, vapor density and temperature can be inferred. This results in a vapor density of the primary plume of $\sim 3 \times 102^{0} \mathrm{~cm}^{-3}$ at the vapor front and $10^{21} \mathrm{~cm}^{-3}$ near the surface. The electron temperature and density measurements yield $3.5 \mathrm{eV}$ (peak) and $4.2 \times 10^{18} \mathrm{~cm}^{-3}$ at a laser intensity of $10^{10} \mathrm{~W} / \mathrm{cm}^{2}$. With these values of vapor density and electron temperature and density, photoionization is predicted to dominate the laser absorption over inverse bremstrahlung, consistent with our one-dimensional model. At $10^{10} \mathrm{~W} / \mathrm{cm}^{2}$ and just after the laser pulse has terminated, we infer from our measurements an absorption depth of only 20 microns versus a vapor plume dimension of greater than 500 microns.

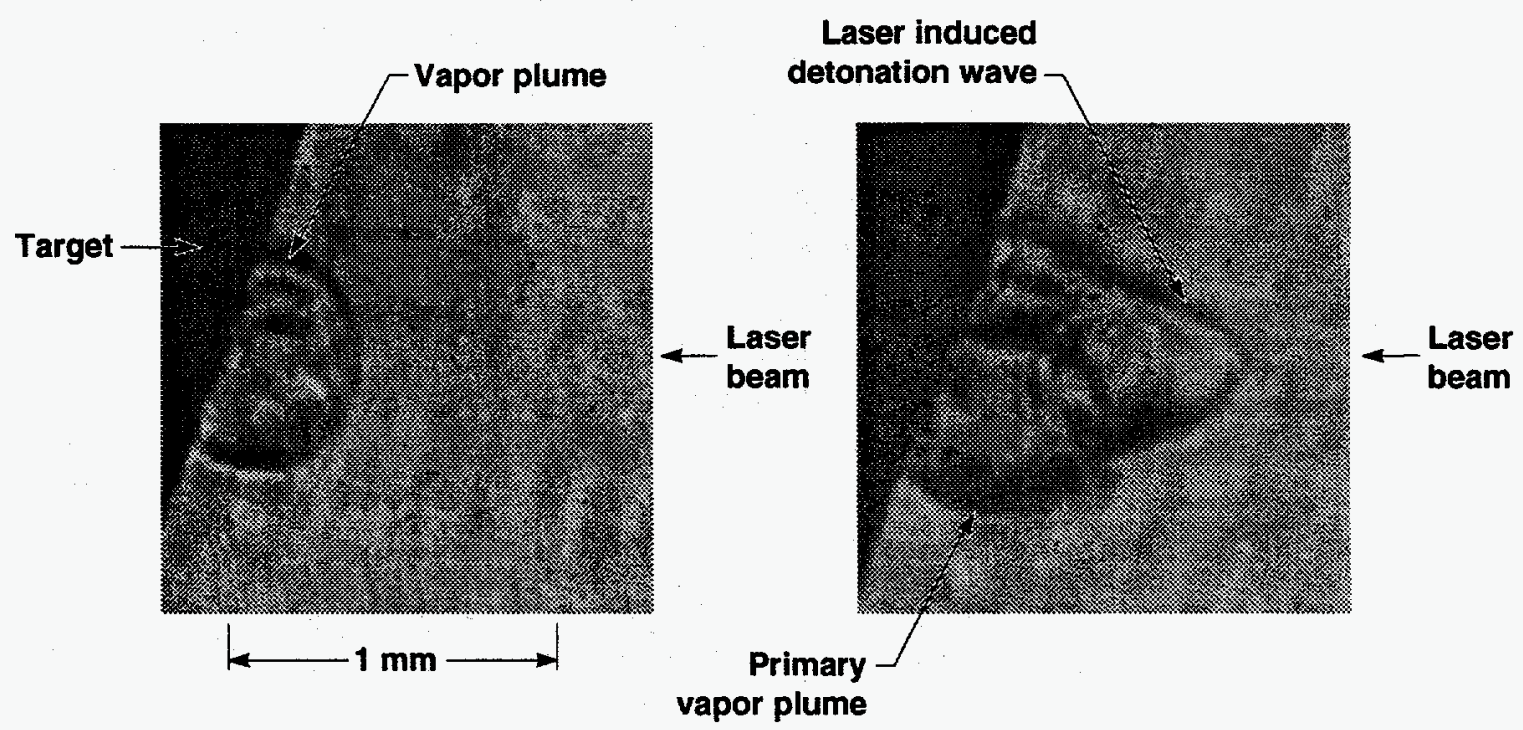

Figure 3. Shadow image of a copper laser produced vapor plume from an aluminum target. Both images produced at $\mathrm{t}=50 \mathrm{~ns}$ (a). Image produced with a laser intensity of $0.93 \times 10^{9} \mathrm{~W} / \mathrm{cm}^{2}(\mathrm{~b})$. Image at a laser intensity of $7.3 \times 10^{9} \mathrm{~W} / \mathrm{cm}^{2}$. 


\section{Precision hole drilling with a copper vapor laser.}

Laser drilling has been widely used in industry because of its high production rate, ability to rapidly vary hole size, ability to drill holes at shallow angles, and ability to drill traditionally hard to work materials such as ceramics and composite materials. We have extended this utility to submillimeter dimensions by use of a near diffraction-limited copper laser and precision wave front tilting technology.

The ability to focus a laser beam is one of the most important characteristics of a laser micromachining system. In order to produce a small, circular laser focus spot with a reasonable focal depth ( $20-30$ times the spot size), the laser beam needs to be near diffraction limited with wavelength in the visible or UV range. To minimize the heat affected zone, the duration of laser pulse needs to be less than a few microsecond such that heat conduction to the material during drilling is negligible. Multi-kilohertz operation is preferred to remove the material in a more controllable fashion, such that material removed during each pulse is small while the processing speed is maintained because of high pulse rate. A copper laser, with its high repetition frequency $(4-20 \mathrm{kHz})$ and short output pulse $(30-100 \mathrm{~ns})$ in the visible spectrum, has been considered an ideal tool for laser micro-machining $[6,7,8]$ However, the difficulties in control of CVL beam quality and in optimization of processing parameters has prevented it from generating repeatable high precision result. Our recent development of high-beam quality CVLs and precision wave front tilting technology has led to success in laser precision micro-fabrication.

The schematic of our copper laser based micro machining system [9] is illustrated in Figure 4. An injection controlled copper laser oscillator [10] with near-diffraction-limited beam quality is used in this system. A power-in-the-bucket measurement indicates $~ 73 \%$ of the laser output is within diffraction limited beam divergence. The laser is designed to be operated between $4-9$ $\mathrm{kHz}$ for various material processing requirements. This laser generates about $30 \mathrm{~W}$ output at wavelengths of $511 \mathrm{~nm}(60 \%)$ and $578 \mathrm{~nm}(40 \%)$. The self-terminated CVL used in our system typically has a pulse duration of $50-70 \mathrm{~ns}$. The laser beam is focused by a diffraction limited achromat on the working piece that typically generates a spot size of approximately 20 microns

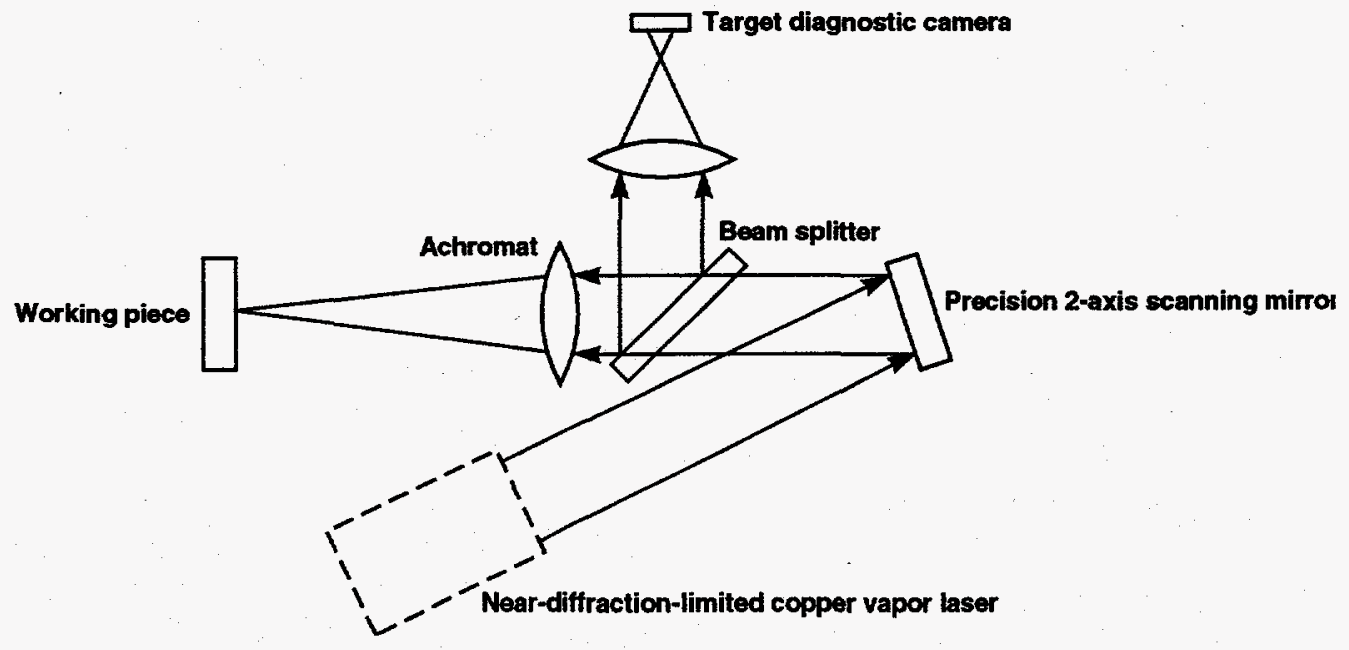

Figure 4. The schematic of a CVL micro-machining system. 
when an $\mathrm{F} / 10$ system is used (i.e., a diffraction limited spot size is about 15 microns). As shown in Figure 4, a precision two-axis scanning mirror is used to tilt the laser wave front before passing through the achromat with an angular resolution better than 5 microradians. This scanning mirror is equipped with a feedback loop to compensate for hysteresis effects. The beam scanning frequency on the work piece can be varied from $1 \mathrm{~Hz}$ to about $100 \mathrm{~Hz}$ depending on application requirement. A camera is used to observe the progress of material processing on the working piece based on reflected laser light.

In copper laser percussion drilling, a stationary laser beam (scanning mirror turned off) is used to drill. Straight parallel holes with aspect ratio better than 40:1 have been repeatedly produced in a variety of steels; $20-25$ micron diameter holes percussion drilled in $1 \mathrm{~mm}$ stainless steel are typical. Because the material removal is mostly through laser ablation, these holes show no measurable heat affected zone. Smaller hole sizes can also be achieved using a lower laser power or faster focusing optics, but this also reduces material penetration with the possibility of generating tapered holes. Since the coupling between the side wall of a drilled hole and the laser beam is very poor due to high incidence angle, our experience indicates that the laser peak power on the hole entrance must be more than a few $\mathrm{GW} / \mathrm{cm} 2$ to avoid hole taper. This intensity is just at the laser detonation threshold.

Assist gas was not found to be essential in CVL micro drilling, but there is evidence that oxygen increases drilling speed due to exothermic reactions. Although straight holes free of recast laser can be produced by a simple CVL percussion drilling at a fairly fast speed, the hole dimension control and hole repeatability are not satisfactory for high precision applications. Typically a tolerance of hole size and roundness of approximately $10 \%$ of its diameter is expected. Higher precision micro drilling must be accomplished by laser trepanning.

Laser trepanning has long been applied in industry to either improve the hole accuracy or to generate large holes, mostly for hole aspect ratio less than 1:1. Precision micro trepanning for higher aspect ratio holes has rarely been accomplished because of difficulties in material penetration and removal. In our investigation, laser trepanning is achieved by tilting the $\mathrm{X}-\mathrm{Y}$ scanning mirror sinusoidally such that the laser spot generates a circular pattern on the work piece. Trepanned holes down to 50 microns in diameter have been drilled this way.

Figure 5 illustrates three CVL trepanned holes with 185 micron diameter in $1 \mathrm{~mm}$ stainless steel. The sample was ultrasonically cleaned after drilling without additional post processing. Minor edge erosion with depth less than 10 microns was found on the laser entrance side as shown in Figure 5a. However, examination of sectioned holes indicated the material underneath of this area was not affected. The holes on the laser exit side, shown in Figure 5b, demonstrate extremely well defined circular hole pattern without erosion. Measurements indicates that both the entrance and exit hole have a roundness error of about 5 microns caused by various mechanisms.

It is obvious that the geometry of the entrance hole is predominately determined by the laser scanning pattern and the shape of a laser spot. Because of the existence of some residue hysteresis of our scanning mirror system, the laser scanning pattern actually has a $\sim 2 \%$ roundness error that explains the dimension error of the entrance holes shown in Figure 5a. On the other hand, the geometry of the exit holes, although primarily controlled by the laser scanning pattern, is also strongly affected by the polarization state of the laser beam. Because of the difference in surface absorption between $S$ and $P$ polarized beam, especially at high incident angles, the laser beam 

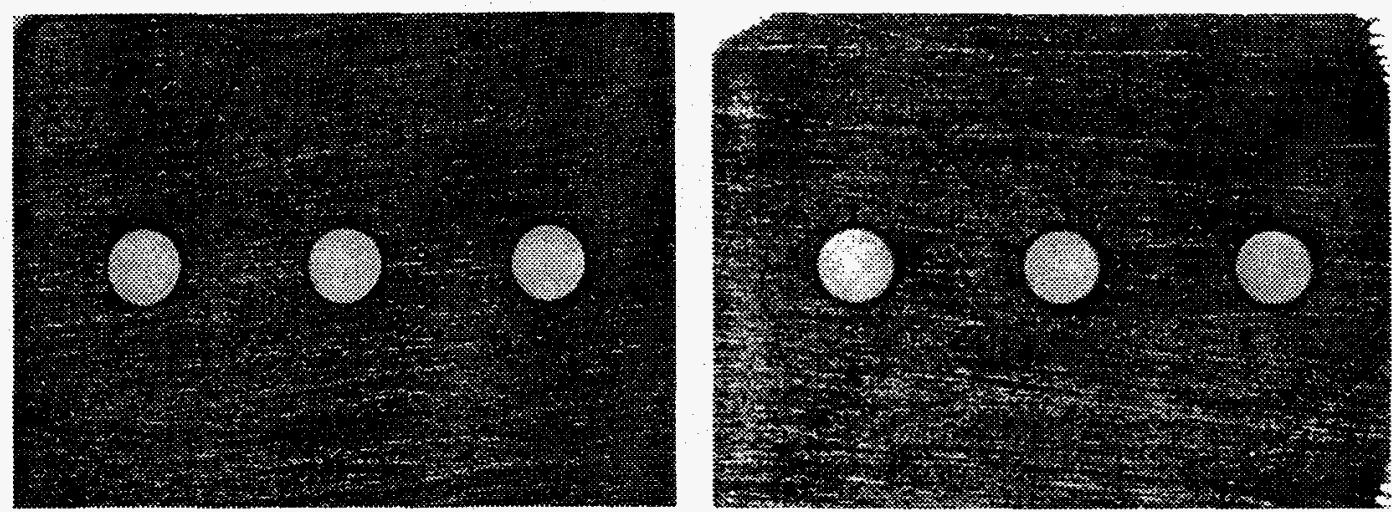

Figure 5. Precision laser trepanned holes with hole diameter of $\sim 200$ microns; (a) laser entrance side, (b) laser exit side.

material removal is more effective along the beam polarization because of its more effective coupling with the side wall. On the material entrance surface, the laser-material coupling is the same for both $S$ and $P$ polarization because of the normal incidence angle. The geometry of a entrance hole is thus not affected by the state of beam polarization.

Repeatability of hole dimension has been significantly improved with CVL trepanning as demonstrated in Fig. 5. The variations of hole size and shape were almost impossible to measure based on our microscope measuring system. This striking improvement on hole repeatability is believed to be mainly due to the fact that laser trepanning not only performs material removal during the initial drilling phase, but also engages in material trimming and side wall polishing during the later drilling phase.

A section of the trepanned holes indicate a fairly straight side wall with surface roughness measured at 1-2 microns (i.e., peak to valley) which is comparable to the low end of a grinding finish. A minor curvature on the side wall may be caused by the caustic surface of the focused laser beam and can be corrected with a longer focus lens. Detailed examination of the hole section reveals that the recast layer and heat affected zone are minimized to a non-measurable level (i.e., sub-micron). SEM pictures of a CVL trepanned hole clearly show an unaltered grain structure on the side wall as a consequence of effective laser ablation process during CVL trepanning.

In addition to circular holes, we have demonstrated non-circular holes with various geometry's on a $1 \mathrm{~mm}$ thick stainless steel, as illustrated in Figure 6 . These holes were cut by modifying the scanning pattern of the trepanning system to draw the desired shape on the target. Hole aspect ratio higher than 10:1 with no taper has been achieved with these non-circular trepanned holes. Corner rounding effects become more severe as hole size is reduced to smaller than 100 microns. This demonstration of non-circular micro holes with high aspect ratio reveals the great potential in laser trepanning applications and may have significant impact on engineering design that is traditionally limited to circular holes.

Copper laser trepanning represents a great potential in laser precision micro-drilling. Noncircular holes have been drilled by simply changing the laser scanning pattern. The hole quality 


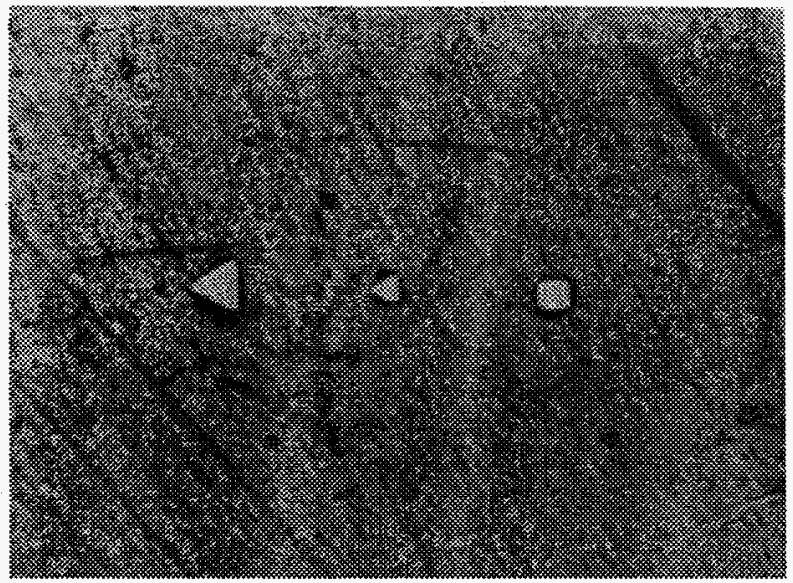

Figure 6. CVL trepanned holes on a $1 \mathrm{~mm}$ thick stainless steel that show a variety of hole geometry's can be drilled with aspect ratio larger than 10:1. Hole dimensions from left to right are $156 \mu \mathrm{m}, 84 \mu \mathrm{m}$, and $90 \mathrm{~m}$.

drilled by this laser micro-machining system is found to be comparable or better than holes drilled by electric discharge machining (EDM). With the flexibility in hole geometry and size, and scalability to higher speed, this micro-machining system offers a superior technique to EDM machines which currently are widely used in industry.

We have found that there are four groups of industries that are interested in this precision drilling technology. They are the automobile and truck engine manufacturers for fuel injectors, the jet engine manufacturers for turbine blade cooling holes, industries that require precision orifices (ink jet, biochemical, etc.), and the electronics industry for "vias" in multi chip modules. Within these industrial segments, demand is for micron precision and drilling rates measured in holes per minute or higher.

\section{Pulsed laser deposition utilizing a high-power copper laser}

We like to think of pulsed laser deposition (PLD) with a copper laser as good utilization of the vapor ejected during precision hole drilling. This is not strictly true, but the same physical attributes that create ablative material removal also cause the transfer of high quality materials in a deposition chamber. As discussed in the first section of this paper, illumination of a target with a copper laser beam quickly heats the surface of targets to above $10,000 \mathrm{C}$. At this temperature most materials have very similar vaporization rates. In PLD the vaporized material is allowed to expand in a vacuum chamber before striking a substrate to be coated. Source material is typically replenished by moving the target relative to the laser beam.

Many high-value coatings have been produced by PLD. Examples are: high Tc superconductors $\left(\mathrm{YBa}_{2} \mathrm{Cu}_{3} 0_{7}\right)$ [11], ferroelectric films for nonvolatile memories $\left(\mathrm{Pb} \mathrm{Zr}_{\mathrm{x}} \mathrm{Ti}_{1-\mathrm{x}} \mathrm{O}_{3}\right)$ [12], and low work function field emitters (DLC) [13]. The majority of studies utilize short wavelength (193 nm [ArF] to $308 \mathrm{~nm}[\mathrm{XeCl}])$ light arriving in $20-50 \mathrm{~ns}$ pulses with peak irradiance of $10^{8}-10^{10}$ $\mathrm{W} / \mathrm{cm}^{2}$ at rates of $5-30 \mathrm{~Hz}$. However, some authors report positive results with green $(532 \mathrm{~nm}$ 
frequency doubled Nd:YAG) radiation sources operated under similar conditions. Typical film formation rates with these laser systems are on the order of $10 \mu \mathrm{m}-\mathrm{cm}^{2} / \mathrm{hr}$.

We have utilized a single copper vapor laser (CVL) oscillator and one high power amplifier for our PLD studies. In this paper we will only review our results on depositing diamond-likecarbon (DLC), ablated from a graphite target. Nominal operating parameters are summarized in Table 1. The optical delivery system was comprised of a discrete optics delivery system and a single $500 \mathrm{~mm}$ focusing lens located adjacent to the vacuum deposition tank. Relatively low irradiance ( $108 \mathrm{~W} / \mathrm{cm}^{2}$, below the laser detonation threshold) on the target was necessary to achieve high deposition rates and good materials properties. This was accommodated by defocusing the beam on the target.

A schematic drawing of the deposition chamber is shown in Figure 7. The laser light is introduced through a fused silica window. The graphite target is a rod of 1-inch diameter that is mechanically rotated at approximately 1 RPS and can be manually moved axially to keep a relatively fresh surface. The laser is aligned to strike the rod off center so that the laser plume is at 45 or 60 degrees to the incident beam. In general, the ablation plumes expand normal to the surface. The substrate to be coated is mounted within a sample port that is easily removed for deposition on multiple substrates. The graphite target to substrate distance is $7.6 \mathrm{~cm}$. Viewports orthogonal to the laser and plume and in the scattered laser direction were used to help diagnose laser alignment, plume generation, and qualitatively assess macroparticle generation. A turbomolecular pump was used to achieve a base pressure of $5 \times 10^{-8}$ Torr. For each set of deposition runs the vacuum chamber was heated up and outgassed. Typical vacuum levels during deposition episodes were in the 10-6 Torr range. To date, no assist or buffer gases have been used. Several different substrates have been coated with DLC. However, consistent with results of others, adherence of the films are substrate dependent.

Our early experiments investigated the deposition of DLC at laser irradiance of $108 \mathrm{~W} / \mathrm{cm}^{2}$ to $10^{10} \mathrm{~W} / \mathrm{cm}^{2}$. We have utilized both electron energy loss spectrum (EELS) and Raman scattering off of the DLC films to help quantify its bond structure. Figure 8 is a representative Raman spectra of our DLC film grown with the above parameters. The EELS spectra and Ramans spectra verify the DLC nature of the film. In addition, it is very hard. We have used a micro indentor to measure the hardness of these films to be $60 \%$ of crystalline diamond, $\sim 58 \mathrm{GPa}$.

We typically control both the target irradiance and number of laser pulses (in combination with a masked silicon substrate) to quantify the volume of DLC grown on the substrates. Its spatial distribution and its growth rate were determined by measuring film thickness and distribu-

TABLE 1. Operating Parameters.

\begin{tabular}{ll}
\hline Spot size on target: & $50-300 \mu \mathrm{m}$ \\
Irradiance & $2 \times 10^{10}-4 \times 10^{8} \mathrm{~W} / \mathrm{cm}^{2}$ \\
Pulse width: & $50 \mathrm{~ns}(\mathrm{FWHM})$ \\
Target speed: & $8 \mathrm{~cm} / \mathrm{s}$ \\
Target - Substrate Distance: & $7.6 \mathrm{~cm}$ \\
DLC deposition rate: & $5.6 \times 10^{-2} \AA$ pulse at $4 \times 10^{8}$ W/cm 2 \\
& $1.0 \times 10^{-3} \AA$ pulse at $2 \times 10^{10}$ W/cm 2 \\
\hline
\end{tabular}




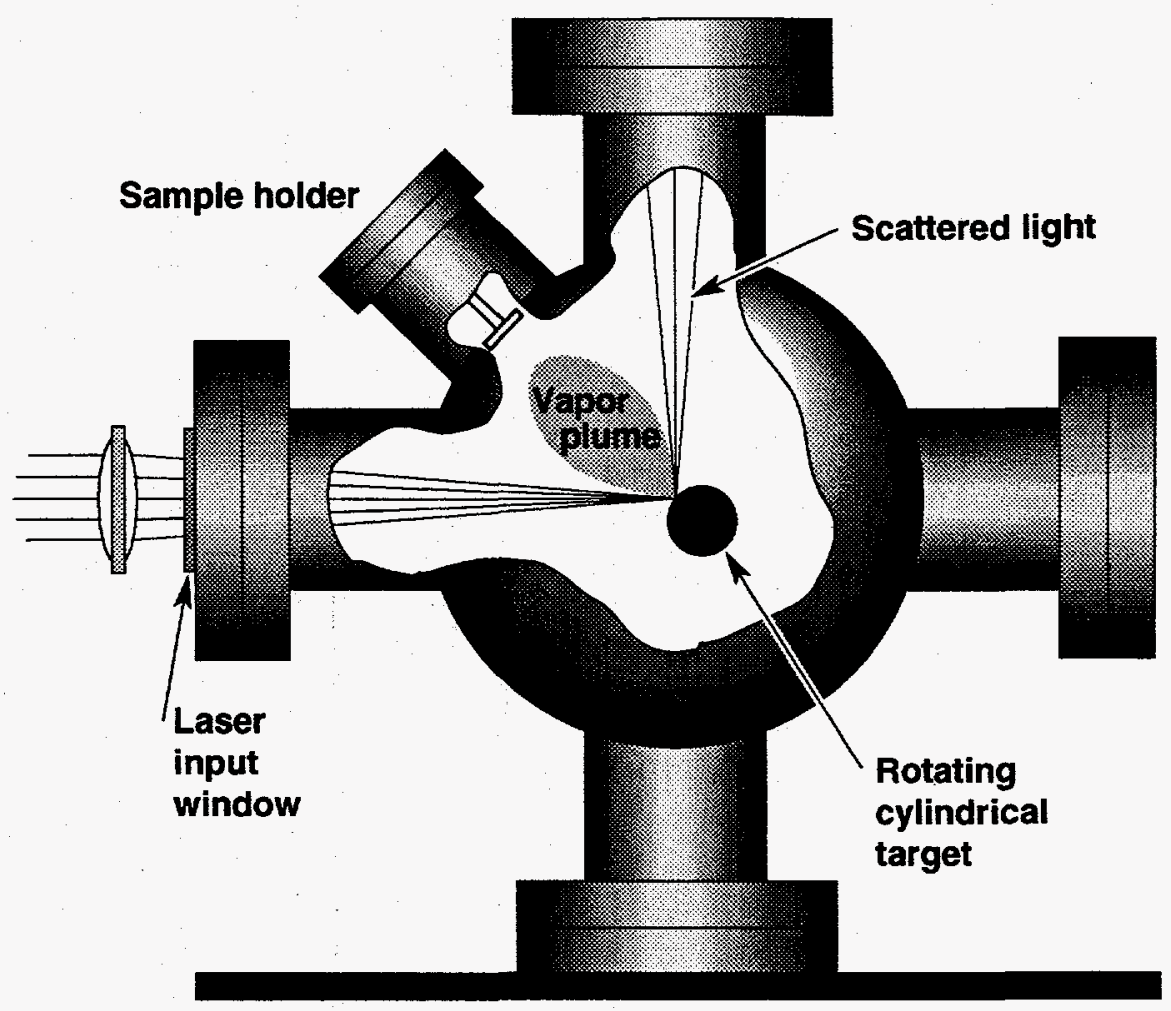

Figure 7. Developmental PLD chamber schematic.

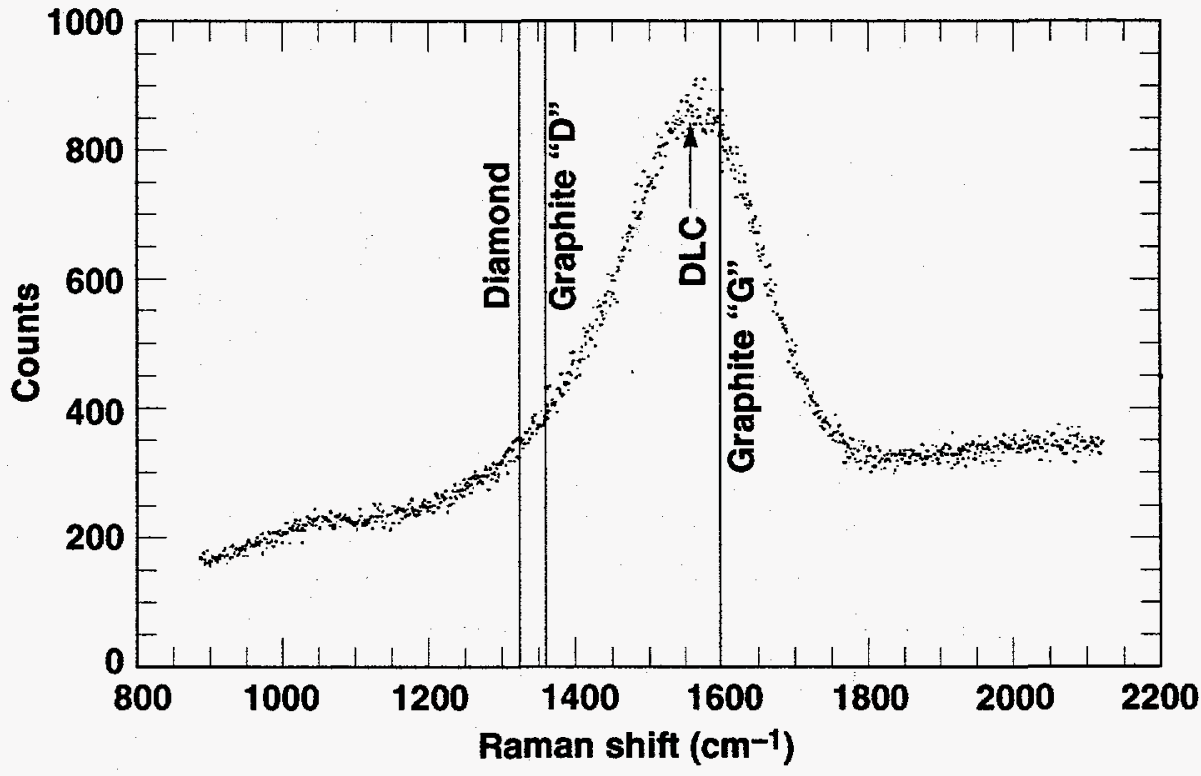

Figure 8. Raman spectra of copper laser produced DLC spectra indicates DLC. 
tion with a diamond stylus profilometer at the step-up provided by the masked area. Figure 9 displays a measured DLC deposition thickness across the substrate. The deposition has a very peaked character typical of PLD. It is this peaked film deposition that makes uniform film growth over large areas difficult. The deposition profile in Fig. 9 has been fit with a plume distribution proportional to $\cos 10 .{ }^{5} \phi$ ( $\phi$ is the angle measured from the target surface normal). After $10^{5}$ laser pulses at $4 \times 10^{8} \mathrm{~W} / \mathrm{cm}^{2}$ (190 W average power), we achieved $410 \mathrm{~nm}$ thickness at the center with half thickness at a radius of $\sim 4 \mathrm{~cm}$. Since our copper lasers operate at $4.4 \mathrm{kHz}, 10^{5}$ pulses represents 23 seconds of elapsed time. Integrating the full volume of material and dividing by the elapsed time yields an average deposition rate of $2 \times 10^{3} \mu-\mathrm{cm}^{2} / \mathrm{hr}$. We have subsequently operated at $100 \mathrm{~W}$ average power at slightly lower target irradiance and have achieved $2.6 \times 10^{3}$ $\mu-\mathrm{cm}^{2} / \mathrm{hr}$. At this rate we produce DLC coatings in minutes that would normally take hours by either low repetition rate lasers or RF plasma deposition (note that materials can have significantly different properties with RF plasma deposition). We have recently produced a $2.5 \mu \mathrm{m}$ thick DLC film on a silicon substrate, with good surface characteristics. This film was grown with 58 seconds of laser on time.

Figure 9(b) displays the measured coating rate for DLC versus laser irradiance on the target. Variations of irradiance were accomplished by defocusing the laser, but total energy on the target was kept the same. Notice the peak in coating rate occurs at just below the measured laser detonation thresholds for aluminum and steel. We expect to measure the threshold for carbon in the near future, but it appears that detonation slows down the vaporization rate of the graphite. We did not measure significantly different DLC properties at these intensities. Atomic Force Microscopy (AFM) was used to measure surface roughness. A $400 \mathrm{~nm}$ thick DLC film has a measured surface roughness (as measured by the AFM) of $\leq 10 \mathrm{~nm}$. We have produced some films with RMS surface roughness as low as a few nanometers.

A promising pulsed laser deposition technology utilizing copper lasers has been demonstrated. Trial runs producing diamond-like-carbon have been encouraging. This technology appears to have significant advantages over other methods in deposition rate and surface morphol-
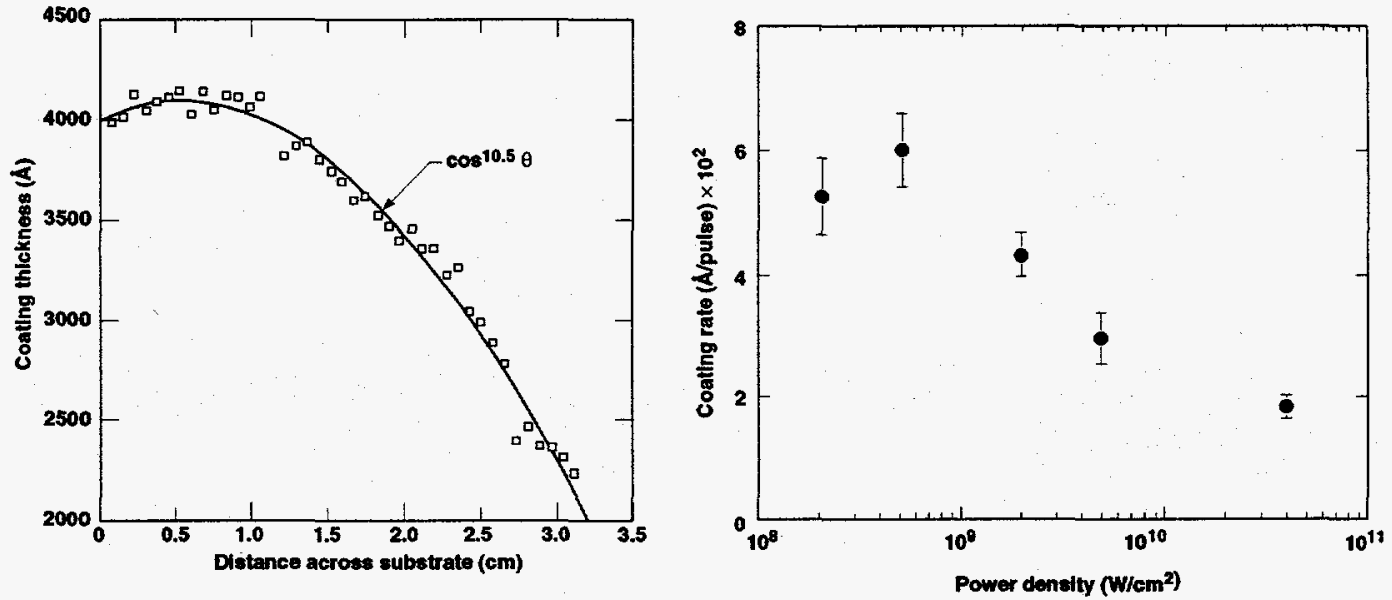

Figure 9. (a) DLC spatial distribution after 105 shots. (b) Coating rate at $100 \mathrm{~W}$ average copper laser power. 
ogy. More work is required to understand the physical characteristics of these coatings to verify their utility. Several proposed uses of DLC, or crystalline diamond films are: low work function emitters for flat panel displays, hard low-friction coatings for machine tool bits or infrared optics, and corrosion resistant coatings for chemical processing systems.

One of the distinct advantages of the PLD process is the near stoichiometric transfer from the ablation target to the desired substrate. We believe that the use of copper lasers allows high deposition rates and consequently a relatively inexpensive coating technique for a large number of high-value thin films. Table 2 serves as an indication of potential thin-film systems and their applications.

\section{Conclusion}

The copper laser has been in existence for nearly thirty years now. With the significant technology development that has gone on in those years, the laser is poised to become a significant source for several emerging industrial applications in addition to laser isotope separation. In this paper we have reviewed the physics of copper laser beams/materials interaction. The laser is capable of high intensity, causing ablative material removal. At sufficiently high intensities, the vapor blowoff causes laser absorption by photoionization and prevents the laser beam from being fully transmitted directly to the part. In this case, electron thermal conduction over longer periods heats the part to lower temperatures. Ablation above the laser detonation threshold does not appear to be as efficient as below it.

TABLE 2. Materials with difficult stoichiometries that have been successfully coated by PLD.

\begin{tabular}{|c|c|c|}
\hline Material & Laser & Use \\
\hline $\mathrm{BaFe}_{16} 0_{19}$ & $\mathrm{KuF}$ & High density hard disk coatings \\
\hline $\mathrm{BaTi0}_{3}$ & Nd:YAG & Optical coatings \\
\hline Cubic BN & $\mathrm{KaF}$ & $\begin{array}{l}\text { High temperature, radiation resistant semiconductors } \\
\text { Cutting tool coatings }\end{array}$ \\
\hline Amorphic C & $\begin{array}{l}\text { Nd:YAG } \\
\mathrm{XeCl}\end{array}$ & $\begin{array}{l}\text { Tribological coatings } \\
\text { Heat sinks } \\
\text { Field emitters for FPD's }\end{array}$ \\
\hline $\mathrm{dd}_{\mathrm{x}} \mathrm{Z}_{1-\mathrm{x}} \mathrm{Te}$ & $\mathrm{KrF}$ & Ir detectors \\
\hline $\mathrm{CoSi}_{2}$ & $\mathrm{KrF}$ & $\begin{array}{l}\text { Low resistivity interconnects for fast switching } \\
\text { Schottky rectifiers }\end{array}$ \\
\hline $\mathrm{MoS}_{2}$ & $\mathrm{XeCl}$ & High resistivity lubricating coating \\
\hline $\mathrm{NbSe}_{2}$ & $\mathrm{KaF}$ & Low resistivity lubricating coating \\
\hline $\mathrm{Pb}\left(\mathrm{Zr}_{0.5} 4^{\mathrm{Ti}} 0.4 \partial_{3}\right.$ & $\begin{array}{l}\text { AfF } \\
\text { Nd:YAG }\end{array}$ & $\begin{array}{l}\text { Piezoelectric devices } \\
\text { Non volatile memory }\end{array}$ \\
\hline $\mathrm{SiC}$ & $\mathrm{XeF}$ & High temperature, wide band gap semiconductors \\
\hline $\mathrm{TiO}_{2}$ & KrF & Antireflection coatings \\
\hline $\mathrm{YBa}_{2} \mathrm{Cu}_{3} \mathrm{O}_{7}$ & ArF, $\mathrm{KrF}$ & High Tc superconductors \\
\hline $\mathrm{Zn} 0$ & $\begin{array}{l}\mathrm{KuF} \\
\mathrm{Nd}: Y A G(2 x)\end{array}$ & $\begin{array}{l}\text { Piezoelectric devices } \\
\text { Phosphors }\end{array}$ \\
\hline
\end{tabular}


The copper laser, because of its ability to produce short pulses and near diffraction-limited beams, is a good tool for micro-machining. In particular, it has the ability to drill holes in difficult materials with very high aspect ratios with virtually no heat affected zone. When the copper laser is utilized in combination with fast tip-tilt mirrors, one can precision trepan holes with $1 \%$ diameter precision and almost arbitrarily shaped cross section.

The same virtues that make the copper laser a good drilling source also make it a good source for pulsed laser deposition. LLNL has utilized $100-200 \mathrm{~W}$ copper lasers to vaporize carbon from a graphite target, producing diamond-like-carbon thin films. Since the pulse repetition rate of the laser is several kilohertz, we can deposit films at $10-50$ times other reported PLD rates. The properties of these films indicate high value for electronics, chemical resistance, and tribological applications. In addition to carbon, there are many high-value thin film materials that may provide a significant market for copper laser technology.

\section{Acknowledgments}

The authors would like to thank E. Fehring, G. Huete, and C. Cochran for excellent technical support and $\mathrm{M}$. Balooch for his outstanding AFM measurements. This work was performed under the auspices of the U.S. Department of Energy by Lawrence Livermore National Laboratory under contract no. W-7405-Eng-48.

\section{DISCLAIMER}

\footnotetext{
This report was prepared as an account of work sponsored by an agency of the United States Government. Neither the United States Government nor any agency thereof, nor any of their employees, makes any warranty, express or implied, or assumes any legal liability or responsibility for the accuracy, completeness, or usefulness of any information, apparatus, product, or process disclosed, or represents that its use would not infringe privately owned rights. Reference herein to any specific commercial product, process, or service by trade name, trademark, manufacturer, or otherwise does not necessarily constitute or imply its endorsement, recommendation, or favoring by the United States Government or any agency thereof. The views and opinions of authors expressed herein do not necessarily state or reflect those of the
United States Government or any agency thereof.
} 
References:

1. Walter, W., Solimene, N., Piltch, M., and Gould, G. (1966) Efficient Pulsed Gas Discharge Lasers, IEEE Journal of Quantum Electronics, 474.

2. Wamer, B.,(1987) Overview of Copper-Laser Development for Isotope Separation, Proceedings of SPIE - Society of Photo-Optic Instrumentation Engineers Vol. 737, 2 - 6.

3. Boley, C. and Early, J. (1994) Computational Model of Drilling with High Radiance Pulsed Lasers, Paper presented at the International Congress on Application of Lasers \& Electro-Optics (ICALEO).

4. Kar, A., and Mazumbder, J. (1994) A Mathematical Model for Nanoscale Particles Formed During Laser Ablation, Physics Review E 49, 410 - 419.

5. Poprawe, R., (1984) Disintegration of Material and Plasma Formation in the Radiation Field of UV-Lasers, Ph.D. Thesis, Darmstadt Technical University.

6. Kupfer, R., Bergmann, H., and Lingenauer, M. (1991) Material Influence on Cutting and Drilling of Metals Using Copper Vapor Lasers, Proceedings of SPIE - Society of Photo-Optic Instrumentation Engineers Vol. 1598, 46-60.

7. Bergman H., and Hartmann, M. (1993) Drilling of Metals with Copper Vapor Lasers, Laser Pracessing Proceedings, TMS Annual Meeting, Denver, Colorado.

8. Pini, R., Salimbeni, R., Vannini, M., and Tou, G. (1992) Copper Vapor Laser High Aspect Ratio Drilling Process on Transparent Materials, Paper presented at the Conference on Lasers and Electro-Optics (CLEO) Los Angeles, California.

9. Chang, J., Martinez, M., Wamer, B., Dragon, E., Huete, G., and Solarksi, M. (1994.) Precision Micro Drilling with Copper Vapor Lasers, Paper presented at the Intermational Congress on Applications of Lasers \& Electro-Optics (ICALEO).

10. Chang, J., and Solarski, M. (1993) A Self-imaged Injection-controlled Copper Laser Oscillator, Conference on Lasers and Electro-Optics (CLEO) Digest, 458.

11. Paine, D.C. and Brarman, J.C. (eds.) 1990, Materials Research Society Symposium Proceedings, Vol. 191, 3.

12. Paine, D.C. and Brarman, J.C. (eds.) 1990, Materials Research Society Symposium Proceedings, Vol. 191, 25.

13. Collins, C.B., et. al., (1989) Applied Physics Letter 54, 216. 